\title{
DEMOCRACIA CROMÁTICA: DISPOSITIVOS E CÓDIGOS DE REPRESENTAÇÃO DA COR PARA PORTADORES DE DALTONISMO E BAIXA VISÃO
}

Fernanda Henriques

Universidade Estadual Paulista "Júlio de Mesquita Filho" (UNESP)

ferdi@faac.unesp.com

Marcella Gadotti

Universidade Estadual Paulista "Júlio de Mesquita Filho" (UNESP)

llamarce.gadotti@gmail.com

Mariana Shizue lamaguti

Universidade Estadual Paulista "Júlio de Mesquita Filho" (UNESP)

marianaiamaguti@gmail.com

Resumo: Este trabalho é fruto de uma pesquisa que preocupa-se por encontrar projetos que buscam suprir as necessidades de identificação cromática sentidas por portadores de daltonismo e de baixa visão. Sabe-se que problemas fisiológicos como o daltonismo e a baixa visão alteram a maneira com que as cores são percebidas. Desta forma, torna-se essencial que o designer pense nas cores de forma inclusiva com o intuito de melhor aprimorar a comunicação para o usuário. A cor desempenha um papel crucial dentro do âmbito do design, representando grande parte das reproduções visuais produzidas e auxiliando na diminuição do tempo de reação de uma mensagem. A cor pode ser elemento responsável por organizar, expressar, impressionar e constituir informações para que o meio de comunicação se torne mais eficiente e enfática (FARINA, RODRIGUES \& FILHO, 2006; apud. MAIA 2012). Uma vez ocorrendo um problema na comunicação da cor enquanto informação, a eficácia da mensagem tornase comprometida ou mesmo perdida. Dado o entendimento da importância da cor como elemento de informação e a necessidade de projetar para aqueles que têm dificuldade de enxergá-las, o processo metodológico também incluiu a reflexão sobre a compreensão da cor por meio de diferentes abordagens. Observou-se o funcionamento prático e conceitual em artifícios tecnológicos como óculos corretores de daltonismo já disponíveis no mercado assim como sistemas de representação gráfica das cores via símbolos e códigos. Como resultados, verificamos que os casos estudados demonstraram que há espaço para o design promover produtos e serviços mais democráticos e acessíveis, valorizando assim a independência física e emocional para os usuários garantindo a melhor interpretação do conteúdo.

Palavras-chave: Design Inclusivo, Cor, Daltonismo, Baixa visão. 
Abstract: This study is the result of a research that is focused on finding projects that provide alternatives to the needs of chromatic interpretation felt by individuals with visual impairment and color blindness. It is known that physiological problems such as color blindness and visual impairment alter the way people perceive color. Is this manner, it is essential for designers to think about color in an inclusive aspect with the purpose of improving the communication to the user. Color has a crucial role inside the scope of graphic design, it represents a great part of the visual reproductions absorbed and helps to reduce the reaction time of a 2 message. Color may be the key element to organize, express, impress and build information so that the means of communication become more efficient and emphatic (FARINA, RODRIGUES \& FILHO, 2006; apud. MAIA 2012). Once a problem on color communication as information is found, the effectiveness of the message might be lost or compromised. Given the understanding of the importance of color as an element of information and the need to design for those that struggle to see them, the methodologic process of this study also includes critical thinking about the comprehension of color through different approaches. It was observed the practical and conceptual functioning of technological devices such as color blindness correction glasses already available at the market and graphic representation systems of color via symbols and codes. The cases studied indicate that there is space for design to promote products and services more democratic and accessible to the public, enhancing the user's emotional and physical independence and establishing a better interpretation of the content.

Keywords: Inclusive graphic design, Color, Color Blindness, Visual Impairment

\section{INTRODUÇÃO}

O Há poucas décadas, era comum o uso de imagens em preto e branco em publicações e em visores de aparelhos eletrônicos devido às limitações das tecnologias disponíveis no momento. Entretanto, com o recente avanço da indústria gráfica e da tecnologia, a cor passou a ser empregada com mais frequência e flexibilidade. A cor desempenha não só um papel estético, mas também um caráter informativo e organizacional. O uso da cor em projetos de design se dá em vários cenários, desde os já citados aparelhos eletrônicos e as publicações até nos sistemas de sinalização de espaços públicos como parques, universidades e metrôs.

Dentro de projetos de design, a cor pode indicar hierarquia e organização da mesma maneira em que pode orientar o usuário pelo espaço. Ela caracteriza-se por buscar a satisfação informacional de indivíduos através da análise, planejamento, apresentação e compreensão de uma determinada mensagem conforme seu conteúdo, linguagem e forma. Desta maneira, busca-se assegurar a satisfação do usuário e a sua compreensão sobre a informação disponível (PETERSON, 2007 apud MAIA 2013). 
A necessidade de se pensar no design gráfico de forma inclusiva se torna cada vez mais importante para que se permita uma comunicação visual eficiente, uma vez que dificuldades na percepção cromática podem afetar atividades diárias dos indivíduos. Segundo MAIA (2013), somente no Brasil pelo menos $10 \%$ da população é daltônica. Mesmo dentro da parcela que não possui a anomalia, a visualização da cor varia muito de pessoa para pessoa. Devem ser levadas em consideração as limitações visuais advindas da idade e de problemas físicos sejam eles hereditários ou adquiridos ao longo do tempo como a baixa visão. Segundo dados do Color Universal Handbook (EIZO, 2006), devido a melhoras na expectativa de vida, o número de idosos tende a aumentar e consequentemente, o número de pessoas com baixa visão.

As limitações que antes eram impostas pelos produtos e ambientes projetados sem consideração pelas necessidades dessa parcela da sociedade passaram a ser notadas e modificadas. Como característica, o produto do design inclusivo não precisa de adaptações especiais nem de ajustes para que uma pessoa com condições ímpares possa fazer uso em sua totalidade. Assim sendo, designers necessitam conciliar as questões sobre diferenças físicas, sociais e culturais ao processo de design aperfeiçoando assim os métodos projetuais mais adequados para o desenvolvimento de produtos inclusivos. Considerando-se a importância da cor em projetos gráficos, o presente estudo analisa o design gráfico inclusivo voltado para as cores via o uso de estratégias como a representação de cores via símbolos e alternativas de escolha de paletas de cores que não apresentem confusão para nenhum dos três tipos mais comuns de daltonismo.

\section{DESENVOLVIMENTO}

Levando-se em conta as questões fisiológicas que influenciam a percepção da cor no daltonismo e na baixa visão e o papel da cor enquanto agente transmissor de informação, encontra-se no design inclusivo a competência de promover projetos democráticos nos quais anseia-se pela garantia da melhor interpretação do conteúdo de maneira que este seja acessível para todos.

O procedimento do estudo baseia-se em pesquisas bibliográficas sobre o papel da cor no design gráfico e no design gráfico inclusivo. Os estudos de caso analisados promovem soluções de natureza tecnológica ou gráficas às dificuldades sentidas por daltônicos para distinguir certas cores.

\subsection{Metodologia}

Segundo BARROS (2006, p. 15), a cor é uma ferramente importante para a transmissão de ideias e informações. Desta maneira, viu-se necessária a compreensão prévia dos problemas de percepção cromática mais recorrentes, o daltonismo e a baixa visão bem como conceitos de design inclusivo.

A fim de melhor compreender o papel da cor no design da informação com foco nos daltônicos, foram consultadas as reflexões de Maia (2012 e 2013) e da Organização que promove projetos de design acessíveis a todos os públicos, principalmente os daltônicos, a Colour Universal Design Organization. As informações 
referentes aos conceitos de design inclusivo foram analisadas sob a ótica de SOUZA ${ }^{1}$ (2011) e dos criadores dos sistemas ColorADD e Feelipa, Neiva e Pires respectivamente.

Logo, com o intuito de garantir consistência sobre entendimento do design universal para o uso de cores, a metodologia foi baseada em análise bibliográfica referente aos temas como: a) relação entre a cor e o design de informação; b) Design Inclusivo; c) Daltonismo e baixa visão; d) Sistemas gráficos de representação cromática via símbolos; e)Tecnologias que auxiliam a visão de cores.

\subsection{Design Universal e Inclusivo}

Design Inclusivo apresenta uma abordagem geral que permite aos designers garantir o atendimento de necessidades do público mais amplo possível. O próprio Design Council reconhece os conceitos de Design Universal e Design Inclusivo como equivalentes apesar dessa leve diferença cultural.

Cabe ressaltar que o design inclusivo abrange áreas diversificadas, desde produtos até ambientes. Segundo Souza (2011), as mudanças sociais, demográficas, legislativas e econômicas ocorridas em relação aos idosos e pessoas com deficiência durante o século $X X$ criaram as raízes do Design Inclusivo, uma vez que houve um grande aumento na expectativa de vida da população e um grande contingente de veteranos de guerra com dificuldades e deficiências físicas como resultado das duas grandes guerras.

Segundo o autor, a diferença entre os termos Design Universal e Design Inclusivo é sutil, e se trata da abordagem feita ao projeto, porém, Ressalta-se que ambos os campos do design há o mesmo objetivo: um design para todos. Segundo o Design Council (2010, apud SOUZA, 2011) ao passo que o Design Universal se trata de uma abordagem em relação ao processo de desenvolvimento calcado sob uma perspectiva voltada ao usuário.

O design Inclusivo visa o benefício e conforto do usuário enquanto indivíduo, porém a sua importância estende-se logo à sociedade em si. A prática do design inclusivo proporciona independência física e emocional aos usuários aumentando a auto-estima e dignidade das pessoas, dessa maneira o design torna-se mais democrático e flexível.

\subsection{Baixa visão e Daltonismo}

A baixa visão e o daltonismo são problemas fisiológicos que acarretam na dificuldade de ver ou distinguir certas cores e tonalidades. Segundo KULPA (2009 p. 56), a baixa visão consiste em uma perda da visão severa que não pode ser corrigida por tratamentos cirúrgicos e clínicos convencionais nem por óculos corretores, podendo ser causada por doenças genéticas ou patologias adquiridas ao longo da vida como glaucoma, catarata, deslocamento da retina ou retinopatia diabética. Embora o portador de baixa visão consiga fazer uso da visão para a execução de determinadas tarefas, dependendo do caso, o indivíduo pode ter o campo e a acuidade visual comprometidos com sintomas que incluem: problemas com a adaptação à luz e ao escuro, dificuldade na percepção de cores, daltonismo, cegueira noturna,

${ }^{1}$ Cultura. Coordenação de Extensão da Escola de Design - Ano 2, n. 2 (jul. 2011) - Barbacena, MG : EdUEMG, 2011. 155 p. Semestral < http://www.uemg.br/downloads/RevistaTransverso-EscoladeDesign2edicao.pdf> Acesso em 07/02/16 
escurecimento da visão, visão embaçada, manchas na frente da visão e perda da visão à distância (CARVALHO, GASPARETO E VENTURINI, 1992 apud. KULPA, 2009).

No caso do daltonismo, existe a dificuldade de se distinguir somente certas tonalidades e estas são definidas de acordo com o tipo de anomalia apresentada. 0 daltonismo, similarmente chamado de discromatopsia ou discromopsia caracteriza-se pela incapacidade de diferenciar algumas ou todas as cores. Sua origem é normalmente genética ligada ao cromossomo $X$ e 0 indivíduo já nasce com esta condição, entretanto, casos como esclerose, lesões no olho e diabetes podem acarretar em baixa visão e em daltonismo. Segundo o site Colour Blind Awareness, cerca de um em cada 12 homens no mundo e uma em cada 200 mulheres é daltônica.

Segundo PEDROSA (2009), no aparelho de visão humano existem três tipos de cones, células detectoras de luz ativadas em ambientes bem iluminadas responsáveis pela visão do aspecto cromático, estes cones são correspondentes às cores azul, vermelho e verde. Por conta do mau funcionamento dos cones existentes na retina, os fótons não podem ser absorvidos e percebidos corretamente. Os tipos de daltonismo existente se relacionam à ausência ou disfunção de um ou todos esses cones. Ainda segundo o autor, os três tipos mais recorrentes do daltonismo são: o tricomatismo anormal, o dicromatismo e a acromapsia. O portador de tricromatrismo, ou tricromacia anormal apresenta um desvio na curva espectral referente ao vermelho e o laranja, o que faz que estas cores sejam substituídas por suas complementares, o verde. Dentro deste caso encontram-se ainda a deuteranomalia, protanomalia e tritanomalia, o dicromatismo é a visão em apenas duas cores, nesta disfunção, todas as cores quentes se identificam com a claridade e são vistas como amarelo e as cores frias são interpretadas como cinza, somente o azul é percebido de forma relativamente normal. A acromapsia é a ocorrência mais rara e também é conhecida como cegueira total de cores, neste caso o portador tem os cones que compõem a fóvea retiniana completamente desprovido de função o que faz com que somente seja percebido tons de cinza (DANTAS, 1996; apud MAIA 2013 p.18).

Dentro do dicromatismo encontra-se a protanopia, deuteranopia e tritanopia, estes apresentam dificuldade de identificação de largas seções do espectro. A protanopia é caracterizada impossibilidade de percepção da cor vermelha, uma vez que apresentam uma falta de cones longos (entre 564 e 580 no espectro visível da luz) que são responsáveis pela percepção desta cor (ASATO \& GONÇALVES, 2009, apud MAIA 2013 p.19); na deuteranopia, os cones médios (534 a 454 nm) apresentam uma deficiência que resulta na impossibilidade da identificação da cor verde, por fim a tritanopia, por conta da ausência dos cones responsáveis pelos comprimentos de onda curta (420 e $440 \mathrm{~nm}$ ), caracteriza-se pela incapacidade de percepção do amarelo e do azul.

De acordo com o Colour Universal Design Organization, a maior parte dos portadores de daltonismo apresenta dificuldades de distinção entre o verde e o vermelho como é o caso da protanopia e deuteranopia, já a tritanopia que se apresenta em pessoas com problemas no gene opsina azul atinge somente cerca de $0.0001 \%$ dos daltônicos.

É normal o indivíduo levar anos para perceber que é portador da deficiência. Segundo o Hospital de Olhos $^{2}$, o diagnóstico é feito por oftalmologistas que fazem uso

${ }^{2}$ http://www.hospitaldeolhos.net/noticias-interna.asp?id=268\&palavra=> acesso em 5 de março 2016 
de diferentes tipos testes. Assim como é muito comum que profissionais da área da comunicação visual desconheçam as condições fisiológicas da visão daqueles que são afetados pela deficiência cromática. Para tanto, torna-se necessária a conscientização dos aspectos envolvidos junto às ações que podem ser feitas em prol da inclusão. Portanto, a organização Color Universal Design (2008) informa pontos importantes a serem considerados por designers durante a escolha de cores em projetos projetos de forma inclusiva para deficientes cromáticos. Algumas das condições de visão para o espectro dos portadores protanopia e deutaronopia - daltônicos de verde e vermelho - informadas pela organização são a dificuldade de se distinguir tons intermediários que tenham a mesma intensidade entre o espectro do verde e vermelho. 0 mesmo acontece para cores que tem somente o componente verde ou vermelho de diferente. Por exemplo; azul e roxo (violeta= azul+vermelho).

De maneira a compensar o problema no reconhecimento de tonalidades, daltônicos tendem a ser mais sensíveis às diferenças de brilho e saturação. Comparada as cores com saturação alta, as de baixa saturação são mais difíceis de distinguir como por exemplo o azul claro e rosa claro. Para compensar a falta de cones verdes ou vermelhos, os daltônicos tendem a depender mais das informações obtidas pelos cones azuis, assim, eles são mais sensíveis para distinguir tons de azul do que não daltônicos. Por exemplo, daltônicos vêem verde e verde-azulado como cores completamente diferentes.

\subsection{Estudos de caso: ferramentas tecnológicas e gráficas que contribuem na identificação de cores}

Foram realizados estudos relacionados à busca de soluções cromáticas para usuários daltônicos. Apesar da anomalia não possuir cura, é possível minimizar o desconforto do daltônico em suas tarefas cotidianas com artifícios tecnológicos como as lentes ColorMax e EnChroma, e com projetos inclusivos voltados à daltônicos e portadores de baixa visão, tais como o Sistema de Identificação de Cores para Daltônicos, ColorADD e o Feelipa.

Considerando as condições fisiológicas encontradas nos portadores de dautonismo e baixa visão, ao passo que é evidente a importância da cor enquanto veículo de comunicação, não podemos nos esquecer que ela em si é uma informação. Pensando nisto, designers têm buscado por soluções que garantam a melhor interpretação do conteúdo.

Enquanto alguém que não vê ou distingue cores pode ser informado que um determinado objeto é vermelho ou laranja via outras linguagens - tais como a palavra escrita, braille, ou som por exemplo - ela não vai necessariamente associar que a mistura do vermelho com amarelo resulta no laranja. Sistemas de representação da cor por meio de símbolos gráficos auxiliam os usuários não só a identificarem a cor do objeto assim como os ajudam a racionalizar sobre a composição cromática promovendo mais autonomia e independência.

O ColorADD e o Feelipa Color Code são sistemas gráficos de representação de cores via símbolos. O primeiro, criado pelo pesquisador português Miguel Neiva em 2008, tem como base um sistema que faz uso de elementos monocromáticos representantes das cores primárias azul, verde e vermelho, além do preto e branco que quando combinados representam todas as outras tonalidades utilizadas no dia a dia. 
Em entrevista online ${ }^{3}$, Neiva explicou a importância da inclusão no ColorADD que tem o objetivo de empoderar e dar independência ao usuário, o fato do sistema fazer uso somente com uma forma de linguagem gráfica de códigos permite que seja realmente universal, uma vez que pessoas de qualquer cultura, analfabetas e que falem qualquer idioma podem compreendê-lo sem dificuldades.

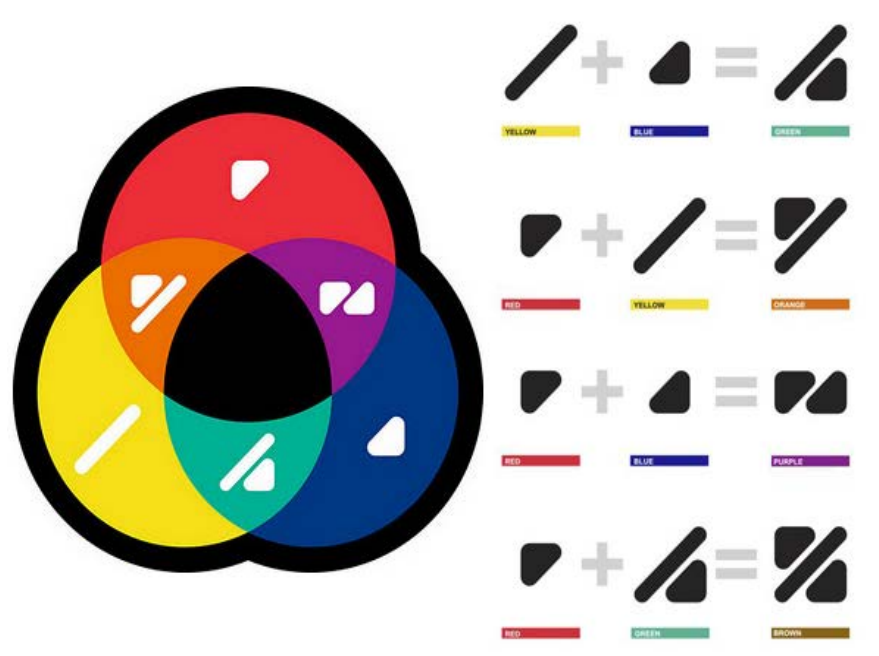

Figura 1. ColorADD (Fonte: coloradd.net)

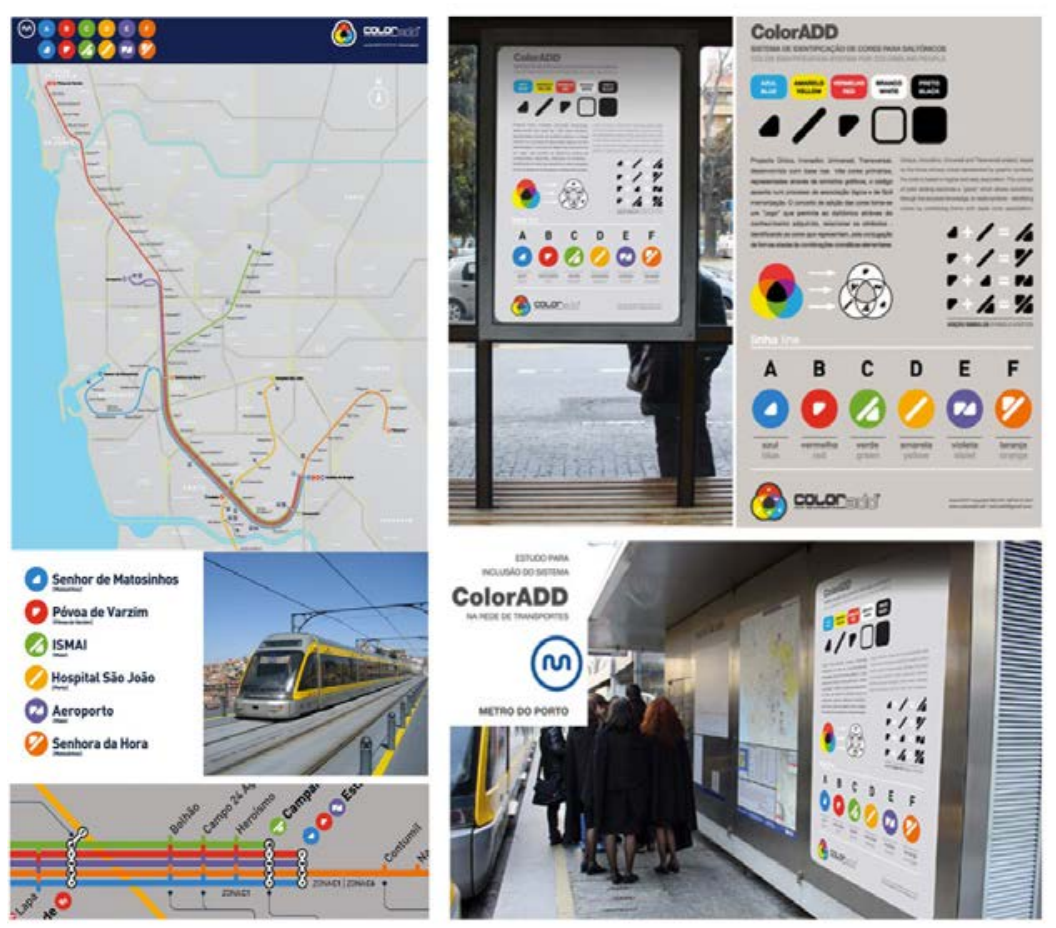

Figura 2. ColorADD aplicado a sinalização do metrô de Porto (Fonte: coloradd.net)

O ColorADD já é aplicado no sistema de sinalização do metrô da cidade do Porto, em Portugal; no hospital São João em Porto e na Biblioteca Escolar EB1 no 2 de

${ }^{3}<$ https://www.youtube.com/watch?v=gyX2ntGDNhQ\&ab_channel=AlexandreMartins $>1080$ segundos.com Miguel Neiva 
Mem Martins, em Sintra e em 2012, fez parte da sinalização dos Jogos da CPLP, em Mafra. A licença do ColorADD também é vendida para empresas, sendo assim, aplicado em lápis de cor, embalagens de tinta, sinalização de emergência, jogos de carta e etiquetas de roupas.

Com o mesmo intuito de tornar a cor acessível à todas as pessoas, a designer Filipa Nogueira Pires, em parceria com o Hellen Keller Center - uma escola dedicada à integração de crianças com deficiências visuais-, desenvolveu o projeto Feelipa Color Code em 2009.

O código Feelipa foi elaborado com o propósito de garantir maior independência não só aos daltônicos mas, também, a todos aqueles que possuem problemas de visão, incluindo usuários cegos e com baixa visão. Para atender as necessidades cromáticas de maneira eficiente facilitando o reconhecimento e o aprendizado de cores, a linguagem é composta por relevo para um reconhecimento tátil e funciona de forma lógica associando cores as formas geométricas simples que podem ser reconhecidas independentemente da posição ou orientação no objeto.

Observa-se que tal projeto possui semelhança com as aulas da Bauhaus uma vez que o sistema representa as cores primárias como as formas geométricas básicas, o quadrado vermelho, triângulo amarelo e círculo azul.

Segundo LUPTON e MILLER (2008), as formas e cores são uma sentença elementar da "linguagem" da visão, um código de formas direcionadas mais à percepção biológica do que ao intelecto direcionado, um sistema análogo à linguagem verbal. Partindo deste princípio, percebe-se que a designer expandiu a linguagem para um vocabulário que suporte cores compostas e secundárias. Para demonstrar a adição de duas cores, juntam-se as formas. Por exemplo, a representação gráfica do laranja dar-se-á no desenho de um trapézio para cor que é resultado da adição do vermelho com amarelo, ou seja, um quadrado incorporado a um triângulo.

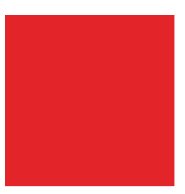

Vermelho

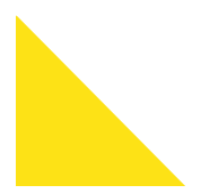

Amarelo

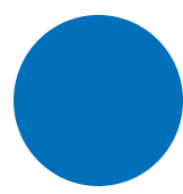

Azul

Figura 3. "Representação gráfica das cores primárias no código Feelipa” (Fonte: feelipa.com)

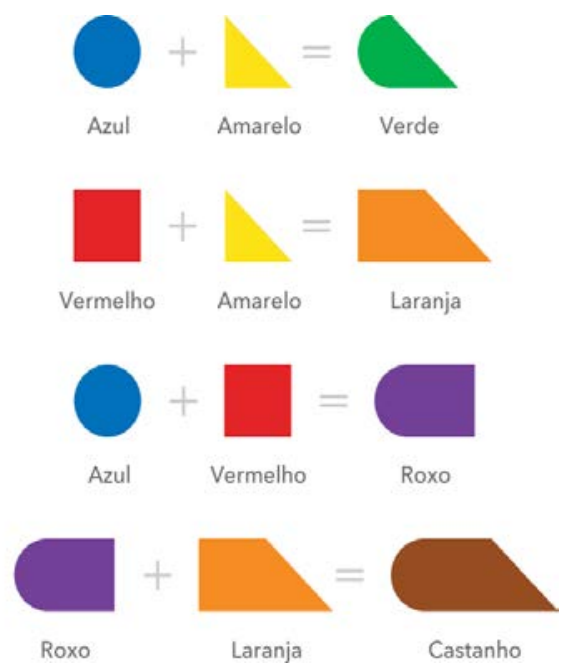

Figura 4. Representação gráfica da adição das cores no código Feelipa (Fonte: feelipa.com) 

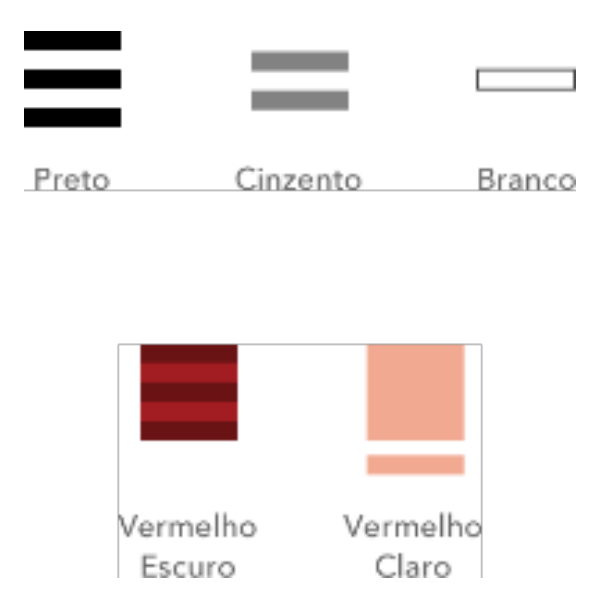

Figura 5. “Representação tátil do código Feelipa” (Fonte: feelipa.com

Diferente da abordagem didática dos dois sistemas acima citados, encontramos dispositivos que fazem uso da tecnologia como um facilitador imediato. Observa que o uso destes produtos não requer que os indivíduos se familiarizarem e aprendam uma nova linguagem, a percepção da cor é feita em nível físico.

As lentes de óculos corretivas Colormax são fabricadas pela Color Vision Technologies. Segundo Dr. Azman, desenvolvedor da Colormax, as lentes funcionam mudando a composição espectral dos cones a fim de realçar a diferenciação das cores, os filtros corretivos do sistema, mudam o comprimento de onda das cores. Os filtros projetados melhoram a capacidade perceptiva das cores somente para daltonismo do tipo protano-deutano (vermelho e verde), portanto não servem para casos com acromatopsia ou tritanopia. As lentes, no entanto, auxiliam apenas na distinção de cores indistinguíveis, adicionando brilho à visão, porém não permitindo a percepção igual à de uma retina saudável (MAIA, 2013 p.23).

As lentes EnChroma, desenvolvidas por McPherson, possuem um mecanismo de filtros corretivos para verde-vermelho semelhante as das Colormax, porém funcionam por meio da colocação de uma banda de absorção nas lentes que captura a luz deixando passar apenas o suficiente para sensibilizar os fotoreceptores e corrigir defeitos na visão. Esse recurso foi capaz de resolver o problema na visão de cerca de $80 \%$ dos clientes, entretanto, segundo o site oficial da marca, são disponibilizados 60 dias de garantia para retorno para casos de daltonismo em que os óculos não são capazes de resolver a dificuldade de visão cromática.

As abordagens observadas nesses estudos de caso sanam de maneiras e porém eficientes as necessidades de visão cromática sentidas por daltônicos. Enquanto as lentes ColorMax e EnChroma atuam na percepção da cor de maneira imediata e física, fazendo com a pessoa enxergue ativamente a cor de maneira semelhante a uma pessoa com visão padrão, os sistemas gráficos de representação cromática Feelipa Color Code e ColorADD, possuem um caráter educativo e da mesma forma que uma nova linguagem, necessitam ser aprendidos.

\section{CONCLUSÃO}

Problemas fisiológicos que acarretam na dificuldade de interpretação e visão cromática são recorrentes na sociedade. Constata-se então que designers gráficos têm percebido a necessidade de informar a cor com mais precisão ao público - tais quais 
portadores de daltonismo e baixa visão - quando a mesma é usada como elemento principal para transmitir informações, organizar elementos e representar hierarquias e estruturas.

Dentre os projetos estudados, nota-se que foram seguidos dois tipos de abordagens. A primeira mostra-se mais didática através dos sistemas de códigos ColorADD e Feelipa. Os dispositivos de representação gráfica via símbolos não dão ao usuário a habilidade de enxergar a cor porém, passam a informação cromática por meio de um código de símbolos. Desta forma, a pessoa compreende não somente que determinado objeto é verde mas, também, entende que a cor verde é composta de azul e amarelo. No segundo tipo, vê-se uma performance facilitadora que atua de maneira física na percepção da cor. A tecnologia das lentes ColorMax e EnChroma proporciona aos daltônicos a oportunidade de ver cores de uma maneira semelhante a uma pessoa com a visão padrão.

Ambas abordagens observadas são importantes e demonstram uma preocupação com as dificuldades sentidas por daltônicos entretanto, é possível ponderar o quão acessível é a usabilidade dos projetos. Enquanto os dois primeiros sistemas de cores ensinam a informação da cor e sua composição (sendo o Feelipa o mais universal por ser mais abrangente ao conter tanto informação tátil quanto visual), as lentes estão restritas a somente casos de daltonismo para tons de verde e vermelho (daltonismo do tipo protano e deutano), ignorando desta forma casos de acromapsia e tritanopia, ou seja, casos nos quais o indivíduo vê somente em tons de cinza ou tem dificuldade para tons de azul.

O design está atrelado à sociedade, atuando nas necessidades do usuário. Como os projetos estudados demonstram, a população anseia por sistemas mais inclusivos dando abertura para o design promover produtos e serviços mais democráticos e acessíveis, valorizando assim a independência física e emocional. Levando-se em conta todos os fatores fisiológicos que influenciam a percepção da cor e a importância que ela possui para a transmissão da informação nos meios gráficos, fica incumbido ao designer a responsabilidade de reconhecer que as diferenças de percepção cromática são significativas no projeto.

Assim, cabe ao profissional transformar a mensagem com as ferramentas possíveis de maneira que a informação chegue aos usuários de forma simples, eficiente e assertiva. A linguagem gráfica "como um sistema de signos gráficos é formada pelo significado (conceito) e significante (imagem gráfica)" (ARCHELA, 1999, p.6 apud MAIA, 2013, p. 26). Segundo a autora, uma representação gráfica permite a memorização rápida de um grande número de informações desde que representadas de maneira conveniente e bem ordenadas visualmente. Desta forma, entende-se que os sistemas, ou códigos de representação gráfica de cores, têm de ser disponibilizados para a sociedade de maneira a educar de maneira prática para todos os usuários, uma vez que estes já estarão familiarizados com a linguagem.

\section{AGRADECIMENTOS}

Agradecemos à A Fundação de Amparo à Pesquisa do Estado de São Paulo (FAPESP) pelo apoio. 


\section{REFERÊNCIAS}

BARROS, Lilian Ried Miller. A cor no processo criativo: um estudo sobre Bauhaus e a Teoria de Goethe. São Paulo: Senac, 2006.

COLORADD - ColorADD. Disponível em: <http://www.coloradd.net/> Acesso em 08/07/2015

COLORMAX - Colormax. Disponível em:<http://colormax.org/cbs-news/> Acesso em: 20/02/16

COLOR UNIVERSAL DESIGN ORGANIZATION - Color Universal Design Organization. Disponível em: <http://www.cudo.jp/summary/cudo_e> Acesso em: 28/04/16

EIZO - Color Universal Handbook. Disponível em:

<http://www.eizo.com.tw/products/flexscan/color_vision/handbook.pdf?> Acesso em: $28 / 04 / 16$

ENCHROMA - EnChroma. Disponível em: <http://enchroma.com/> Acesso em: 20/02/16

FEELIPA - Feelipa. Disponível em: <http://www.feelipa.com/> Acesso em 15/03/16 HOSPITAL DE OLHOS - Conheça um pouco mais sobre exames oftalmológicos. Disponível em: <http://www.hospitaldeolhos.net/noticiasinterna.asp? $i d=268 \&$ palavra $=>$ Acesso em 05/03/16

KULPA, Cínthia Costa. A contribuição de um modelo de cores na usabilidade das interfaces computacionais para usuários de baixa visão. 2009. Dissertação (Mestrado em Design) - Universidade Federal do Rio Grande do Sul, Porto Alegre.

LUPTON, Ellen; MILLER, J. Abbott. ABC da Bauhaus. São Paulo: Cosac Naify, 2008.

MAIA, Amanda Fortes Dalla Valle Majó da; SPINILLO, Carla Galvão. O papel do design em projetos para daltônicos. II Conferência Internacional de Design, Engenharia e Gestão para a Inovação, Florianópolis, 21-23 out. 2012.

Avaliação de mapas do transporte de Curitiba: uma abordagem centrada no usuário daltônico. II Conferência Internacional de Design, Engenharia e Gestão para a Inovação, Florianópolis, 21-23 out. 2012.

MAIA, Amanda Fortes Dalla Valle Majó da. O design da informação no transporte público de Porto Alegre: um estudo centrado no usuário. Il Conferência Internacional de Design, Engenharia e Gestão para a Inovação, Florianópolis, 21-23 out. 2012.

Representação gráfica de mapas para daltônicos: Um estudo de caso dos mapas da rede integrada de transporte de Curitiba. 2013. Dissertação (pósgraduação em design) - Universidade Federal do Paraná. Curitiba

REVISTA TRANSVERSO. Núcleo de Design e Cultura. Coordenação de Extensão da Escola de Design - Ano 2, n. 2 (jul. 2011) - Barbacena, MG : EdUEMG, 2011. 155 p. Semestral <http://www.uemg.br/downloads/RevistaTransverso-EscoladeDesign2edicao.pdf> Acesso em 07/02/16

PEDROSA, Israel. Da cor à cor inexistente. Rio de Janeiro: Senac Editora, 2009. 